\title{
LA MIRADA ROMÁNTICA DEL ARQUITECTO ALEMÁN BODO EBHARDT Y SU VIAJE CIENTÍFICO POR LOS CASTILLOS DE ESPAÑA (1930)
}

\author{
Elena DE ORtueta Hilberath ${ }^{1}$ \\ Universidad de Extremadura
}

\begin{abstract}
Bodo Ebhardt fue un arquitecto destacado en las labores de restauración, conservación e investigación de castillos medievales desde la época Guillermina hasta el nacionalsocialismo. Su interés por realizar un compendio razonado, con un análisis in situ de los castillos, le llevó a recorrer casi toda Europa. Su viaje a España, el último de largo recorrido, tuvo como resultado la publicación Spanische Burgenfahrt. Nuestro objetivo es mostrar la intrahistoria de aquel viaje y, en menor medida, del ensayo posterior, en relación con el conocimiento y la interpretación que propone sobre la arquitectura militar hispánica. La contextualización resulta esencial para comprender sus planteamientos teóricos y metodológicos. Por ello, hemos estudiado su método de trabajo, la planificación del viaje o su labor como publicista. Las aportaciones que realizamos se sustentan en el cotejo del libro de Ebhardt con los fondos conservados en su archivo personal.
\end{abstract}

Palabras clave: Bodo Ebhardt; castillología; Edad Media; topografía artística; arqueología de la arquitectura.

\section{THE ROMANTIC GAZE OF THE GERMAN ARCHITECT BODO EBHARDT AND HIS SCIENTIFIC JOURNEY THROUGH THE CASTLES OF SPAIN (1930)}

Bodo Ebhardt was an outstanding architect in the tasks of restoration, conservation and research of medieval castles from the Wilhelmine Period up to era of National Socialism. His interest in producing a reasoned compendium, with an on-site analysis of the castles, led him to travel almost all over Europe. The trip to Spain was the last long-haul one, resulted in the publication Spanische Burgenfahrt. We focus on the study to show the intrahistory of that trip and, to a lesser extent, the subsequent essay, in relation to the knowledge and interpretation it proposes about Hispanic military architecture. Contextualization is essential in order to understand both his theoretical and methodological approaches. Therefore, his work method, his journey plan, or his work as a publicist have been studied. Our contributions are based on the comparison of Ebhardt's book with the holdings kept in his personal archive.

Key words: Bodo Ebhardt; Castle research; Middle Ages; Art History Topography; Architecture Archeology.

Cómo citar este artículo / Citation: Ortueta Hilberath, Elena de (2020): "La mirada romántica del arquitecto alemán Bodo Ebhardt y su viaje científico por los castillos de España (1930)". En: Archivo Español de Arte, vol. 93, núm. 369, Madrid, pp. 21-38. https://doi.org/10.3989/aearte.2020.02.

El despacho de arquitectura de Bodo Ebhardt (1865-1945), situado en Berlin-Grunewald, se transformó con el tiempo en un centro de documentación. Su interés por el estudio de los castillos medievales se acrecentó de forma conjunta al desarrollo de sus proyectos de restauración. El emperador Guillermo II fue su mentor. Entre otras cosas, le adjudicó la reconstrucción de la emblemática fortaleza Haut-Koenigsbourg (Hohkönigsburg) en Alsacia (1899-1909). También la aristocracia confió en él; Karl Eduard von Sachse-Coburg-Gotha le encargó la restauración y

1 eortueta@unex.es / ORCID iD: http://orcid.org/0000-0003-2309-6466. 
ampliación del castillo Veste Coburgo (1909-1925). Incluso, la asociación Vereinigung zur Erhaltung Deutscher Burgen (DBV) ${ }^{2}$, de la cual era presidente, sufragó las obras por él diseñadas para el castillo de Marksburg (1900-1934). A pesar de contar con el apoyo de la clase privilegiada, sus intervenciones fueron censuradas por una parte de la comunidad científica.

La polémica en torno a sus reconstrucciones, las cuales estaban en sintonía con las propuestas del arquitecto francés Viollet-le-Duc (1814-1879), le obligó a justificar sus criterios en distintos foros académicos, como el Tag für Denkmalpflege (TfD). Su conferencia en el segundo congreso del TfD, celebrado en Friburgo en septiembre de 1901, versó sobre el proyecto de restauración del castillo de Haut-Koenigsbourg ${ }^{3}$. Replicó a Paul Clemen (1866-1947) -conservador provincial de Renania (1893-1911) y miembro de la DBV-. En el primer TfD, celebrado en Dresde en septiembre de 1900, este le había reprochado, la reconstrucción del castillo de Marksburg ${ }^{4}$, recordándole que el lema de la DBV era conservar. En Friburgo, Ebhardt alegó que su actuación obedecía a las directrices marcadas por Guillermo II. Por lo tanto, poner en entredicho su labor era reprobar al mismo emperador, quien le había encomendado la reconstrucción y recuperación del pasado medieval del castillo de Haut-Koenigsbourg. A partir de esa fecha, Ebhardt defendió la reconstrucción. No obstante, en su exposición oral diferenció entre una restauración de carácter artístico y otra histórico-arqueológica. Aplicó el método comparativo entre el castillo austriaco de Kreuzenstein, que acababa de visitar, y el castillo suizo de Chillon, que había inspeccionado pocos meses antes, en mayo. El promotor del primero, el conde Johan Nepomuk Wilczek, llevaba años incrementando su colección de restos arquitectónicos y escultóricos procedentes de fortificaciones medievales europeas. El propósito era reutilizarlas para transformar las ruinas cerca de Leobendorf en un artístico castillo medieval. El arquitecto Humbert Walcher von Molthein (1865-1926) ejecutó un proyecto romántico que carecía de un fundamento científico. En cambio, en el segundo, Albert Naef (1862-1936) efectuó un estudio arqueológico antes de intervenir. El resultado de sus excavaciones constituyó la base de su proyecto. Ebhardt consideraba del todo correcta y modélica la propuesta de Naef, quien, también estaba afiliado a la DBV. Durante la conferencia presentó, asimismo, su método de trabajo. Recalcó el valor de la fotografía y del dibujo para examinar los sistemas constructivos. Su análisis se complementaba con la información procedente de las fuentes documentales, sobre todo la cartografía histórica. No obstante, defendió el viaje científico como la mejor fórmula para obtener una visión de conjunto sobre la transformación de las formas y de los estilos en la arquitectura defensiva. Ebhardt alegó incluso que, justo antes del congreso, acababa de inspeccionar un total de 68 castillos. Sumaba ya más de diez viajes de estudio.

Las aportaciones de los viajes de Ebhardt, tanto los organizados para los socios de la DBV como los de estudio, se examinan en publicaciones de su época y actuales. La revista Der Burgwart reseñaba periódicamente los viajes de la asociación. En 1935, salió a la luz el liber amicorum, publicado con motivo del 70 aniversario de nuestro arquitecto5. Sus compañeros le dedicaron una monografía como homenaje por su aportación a la investigación de los castillos. Incluyeron un listado de los sitios visitados desde 1901 hasta $1934^{6}$. Asimismo, subrayaron el empleo del dibujo como herramienta científica ${ }^{7}$; era este un aspecto que desarrolló y mejoró a lo largo de su vida, gracias a sus continuados viajes de estudio. Al mismo tiempo, tuvo cabida el humor con una selección de caricaturas [fig. 1A y 1B].

Sus expediciones científicas son mucho más interesantes al partir de una hipótesis, aplicar un método, y difundir unos resultados. Ebhardt nunca excavó, pero sí midió, fotografió y dibujó hasta la saciedad para comprender el funcionamiento y características de las fábricas medievales. En la historiografía reciente se alude a la importancia de sus viajes. En su tesis doctoral de 1984, Andreas Bekiers

2 A partir de 1953 fue Deutschen Burgenvereinigung (DBV).

3 Tag für Denkmalpflege, 1901: 101-107. Ebhardt en 1905 publicó un texto sobre su teoría de la restauración, el cual completaba su primera visión expuesta en Dresde. Ebhardt, 1905; 1901.

${ }^{4}$ Oechelhäuser, 1910: 56-57. Fischer, 2010: 191.

5 Asimismo se le concedió la Goethe Medaille für Kunst und Wissenschaft. Fischer, 2015: 4.

${ }^{6}$ Ebhardt, et altri., 1935: 27-28. Bekiers, 1984: 156-157.

7 Ebhardt, et altri., 1935: 15-19. 


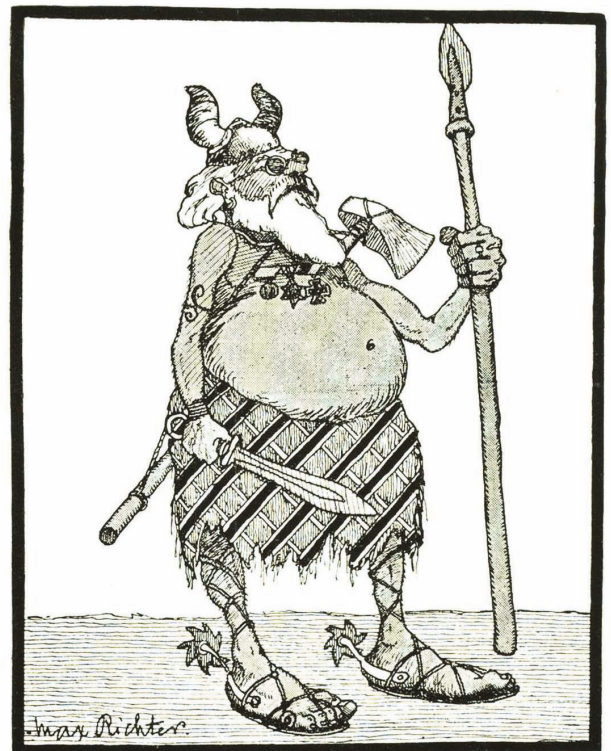

Bodo von Ebhatot

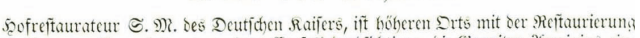

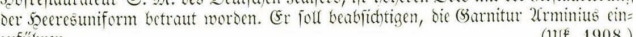
auführen.

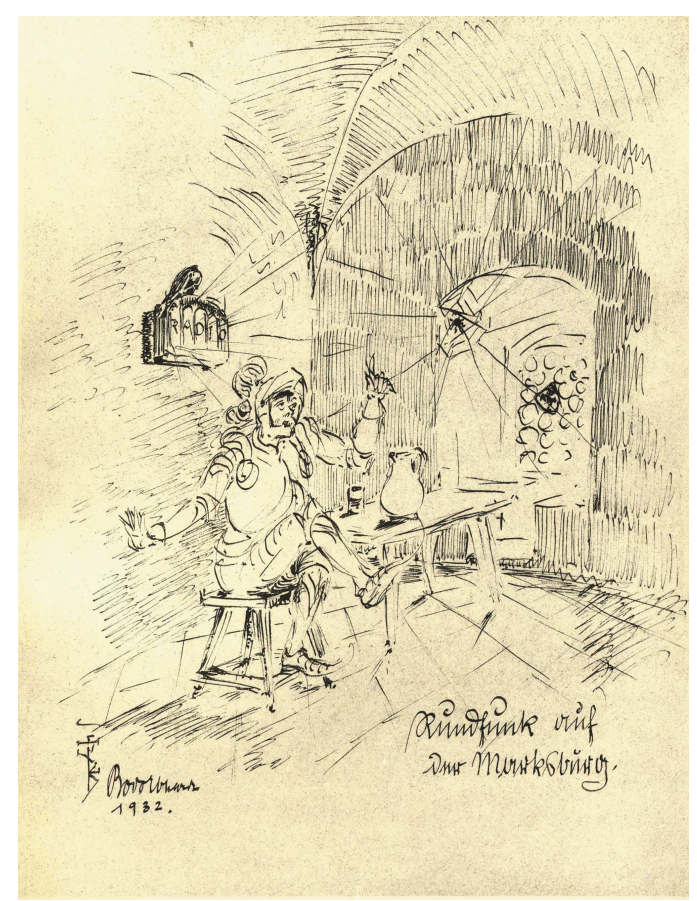

Fig. 1A. Caricatura de Bodo Ebhardt, Max Richter, 1908. Doering, 1925: 179.

Fig. 1B. Radiodifusión en la Marksburg, Bodo Ebhardt, 1932. Ebhardt, et altri. 1935: 80.

hace referencia al viaje de 1897 al Tirol del Sur y a la visita al castillo de Taufers. En la descripción de la misma vemos la relevancia de la visita del lugar ${ }^{8}$. En 1999, con motivo de la exposición del centenario de la DBV, Klaus Tragbar analizó los viajes a Italia, en concreto su cronología y método de trabajo9. En esos años, Ludger Fischer comenzó sus pesquisas sobre Ebhardt. Se interesó en particular por los escritos del arquitecto y por la revisión del estilo medieval ${ }^{10}$. Javier Gil Crespo ha publicado un artículo sobre la figura de Ebhardt en España, con respecto al cual realizamos aportaciones relativas a la lectura de la fuente de estudio: el libro de viaje, y también, entre otras cosas, a la evolución de su pensamiento desde que llegó a España hasta la publicación de este ${ }^{11}$.

La preparación de sus expediciones fue tan importante como el viaje en sí. Planificaba minuciosamente su itinerario con un estudio exhaustivo de las fuentes, de los monumentos que se proponía visitar, del recorrido, y llegaba a cartearse con expertos sobre el tema. Antes de viajar hasta los inmuebles, los evaluaba con criterios estéticos, artísticos o históricos. Aun así, a veces descartaba alguno sin una fundamentación científica, basándose, por ejemplo, en la falta de medios de transporte o vías de comunicación. Ebhardt sistematizó sus investigaciones en forma de archivo. Cada castillo tenía su registro. Este, por regla general, constaba de un formulario, documentación gráfica - como fotografías, planos o dibujos-, textos manuscritos, recortes de prensa, etc. Su método se inspiraba en el de la catalogación monumental y la topografía artística. Este vinculaba las características estilísticas y constructivas con su emplazamiento. Conocía la fotogrametría, y el método desarrollado por Albrecht Meydenbauer ${ }^{12}$. Sin embargo, optó por el dibujo a mano alzada, que le permitía sintetizar las características del castillo.

\footnotetext{
8 Bekiers, 1984: 98.

9 Tragbar, 1999: 72-80.

${ }^{10}$ Fischer, 1999a: 157-169; 1999b: 212-228; 2010: 232-256.

11 Gil, 2016: 245-272. Su análisis toma prestados algunos aspectos del artículo de Link, 2009.

12 Bekiers, 1984: 21-25.
} 
Así, el estudio in situ de las arquitecturas militares fue la base para la redacción de su monografía Der Wehrbau Europas im Mittelalter: Versuch einer Gesamtdarstellung der europäischen Burgen; en la cual trabajó durante casi medio siglo ${ }^{13}$. En su ensayo se constata que describe con mayor detalle los sitios que tuvo la oportunidad de visitar, en comparación con los que no pudo fotografiar ni medir. Para estos últimos se sirvió de comentarios de otros historiadores o de reproducciones artísticas. Esto queda de manifiesto en sus textos sobre los castillos de la península ibérica. Se aprecia un fuerte contraste entre las fortificaciones que visitó entre Madrid y Toledo, frente a los de la frontera con Portugal, hasta donde no llegó.

\section{El viaje}

Ebhardt, a mediados de febrero de 1930, emprendió un viaje de estudio por España. Cruzó la frontera por el paso de Le Perthus inmediato a la Junquera el 21 de febrero de 1930. Regresó a Francia por Irún el 17 de marzo de 1930. Veintiséis días peregrinó por el territorio español para observar, medir, documentar y analizar su arquitectura militar medieval ${ }^{14}$. Había iniciado su viaje en Alemania ${ }^{15}$, cruzando el sur de Francia hacia el Mediterráneo. El viaje de regreso, en cambio, lo hizo bordeando la costa atlántica francesa hasta llegar de nuevo a Berlín, tras atravesar Bélgica y los Países Bajos ${ }^{16} .7 .600 \mathrm{~km}$ recorrió en treintaicuatro días ${ }^{17}$.

La redacción del libro fue casi inmediata: en la primavera de $1930^{18}$. El contenido lo dividió en cuatro apartados: introducción; un viaje a los castillos de España; epílogo e índice (topográfico; ciudades y otros municipios, castillos, iglesias, restos romanos; y onomástico). El segundo apartado es el más extenso y rico. Lo organizó en distintos capítulos que responden a las diversas jornadas: primavera de 1930; a Núremberg; en España; viaje por la costa del Mediterráneo; Valencia; de Játiva a Murcia; Almería; hacia Granada; Zahara; el viaje a Sevilla, Córdoba, Madrid, Toledo, Segovia y norte de España; a través del norte de Francia, y por último, a través de Holanda. La introducción y el epílogo los escribió años después. La clasificación morfológica de los castillos, muchos de los cuales no visitó, su visión de la arquitectura catalana o la introducción de conceptos como el de raza, nos lo constatan.

Fue la primera excursión cuyo recorrido realizó íntegramente en su Nürburg-Mercedes. A los pocos meses, en octubre, publicó una primera aproximación sobre su viaje en coche por España, en la cual describió la ciudad de Almería y su acceso desde Murcia por una carretera de montaña construida en hormigón ${ }^{19}$. Es interesante que resalte las ventajas del transporte en automóvil, lo cual significó para nuestro investigador una forma de ganar tiempo y libertad, al poder visitar un buen número de núcleos urbanos, algunos de ellos dispersos e incomunicados ${ }^{20}$. Los viajes

${ }^{13}$ Kubach/ Verbeek, 1951: 148. El ensayo sobre la arquitectura militar en Europa se considera uno de los estudios más exhaustivos de su época. Es un manual de referencia tanto por el material gráfico como por la bibliografía cotejada. Pero el discurso está superado. Ebhardt, 1939-1958. Hay una reedición con otro formato y sin subtítulo. Würzburg: Flechsig, 1998.

${ }_{14}$ Ebhardt prescinde en su relato de fechas exactas. El último croquis de un castillo francés fue el de Perpiñán, 20/ II/1930, y el primero en territorio español fue la torre dels Encantats en Arenys de Mar, 22/II/1930. En relación a su viaje de regreso indicó la muerte de Primo de Rivera, mientras visitaba San Sebastián. La última lámina fechada fue el castillo de Fuentesaldaña (sic), 15/III/1930. Dibujó después el de Peñafiel, pero no lo dató. No indicó la aduana francesa por la que salió; tal vez cerca de Bayona. Ebhardt, 1934: 31; 128-129. Gil, 2016: 245-272.

15 Salió de Grunewald, Jagowstr. 28. Ansbach es la primera ciudad que menciona. DBV-Archiv Nr. 2253.

16 Ebhardt, 1930: 11-12.

${ }^{17}$ El presupuesto inicial para gastos fue de 81.225 Marco Imperial (RM). Alojamiento y dietas 1.160 RM, y para transporte 80.065 RM (79.800 RM gasolina — un consumo de 30 litros cada $100 \mathrm{~km}$-, 100 RM aceite y 165 RM garaje). DBV-Archiv Nr. 2253.

${ }_{18}$ El manuscrito lo reformuló varias veces. Se aprecia tanto en las pruebas de imprenta (Ebhardt, 1931: 49-50; 1932: s. p.; 1933: 25-31) como en la documentación custodiada en su archivo. DBV-Archiv Nr. 2253; 2240 IV.

19 Ebhardt, 1930: 105-108.

${ }^{20}$ Ebhardt exclamó: ¡Cuánto más excelente es el viaje en coche! y añadió haber visto mucho más que si hubiese viajado en tren. Ebhardt, 1934: 103. 
Fig. 2. La Guardia, vista de las casas cueva, Ebhardt, 1934: n. ${ }^{\circ} 31$.

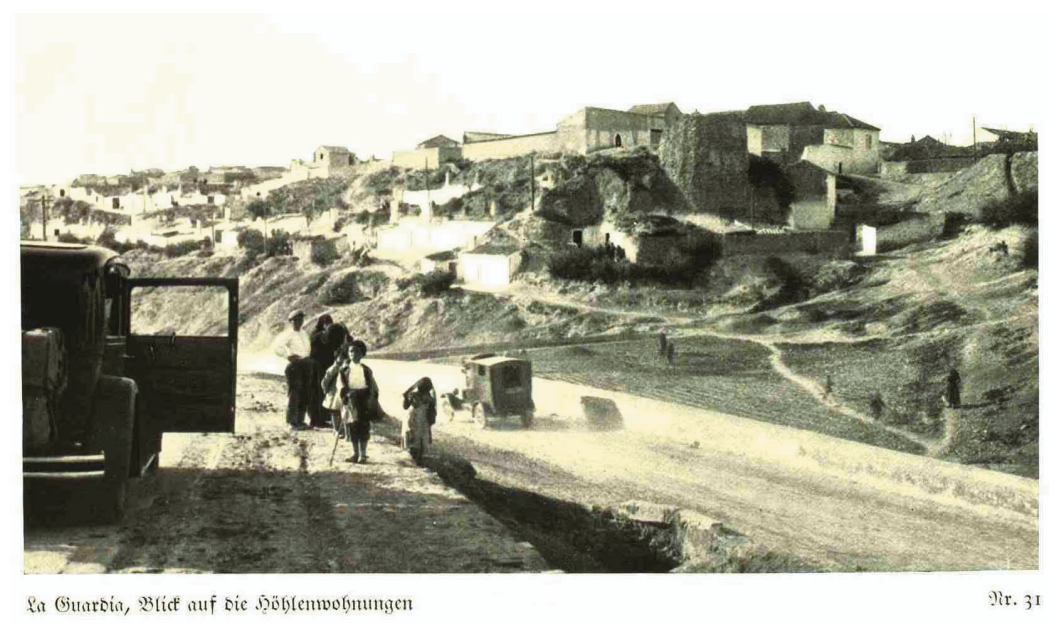

anteriores por Italia o Francia los efectuó alternativamente en ferrocarril y en coche de caballos ${ }^{21}$. Paradójicamente, se trató de su último viaje científico de gran recorrido. En las últimas décadas había viajado por casi toda Europa a excepción de Suecia y de Noruega. El programado viaje a Grecia se vio truncado por el estallido de la II Guerra Mundial ${ }^{22}$ [fig. 2].

El desplazamiento en coche, en esos años, gozaba de una creciente popularidad entre la clase más pudiente. Una de las pioneras fue la princesa Pilar de Baviera, quien realizó dos viajes de carácter turístico-familiar por España —el primero en octubre de 1910, y el otro poco después, en septiembre de 1912-. Años más tarde, durante la primavera de 1927, el Real Automóvil Club de Baviera emprendió una expedición por España. En esa ocasión, el director del club, el comandante Czermak, expuso que la iniciativa no se había limitado a un interés deportivo, sino que se trataba "de un viaje de propaganda de todo lo alemán en el extranjero". Dicha empresa, entre otras cosas, sirvió para fortalecer los vínculos entre los automovilistas alemanes y españoles. Al igual que Ebhardt, apreciaron el inteligente trazado de las carreteras y la calidad de su firme, que, según el club bávaro respondía al "sueño de todo automovilista un poco exigente"23. El club automovilístico consideró su aventura como una actividad deportiva, por ello sus afiliados condujeron sus propios vehículos. En cambio, Ebhardt contrató los servicios del Sr. Koennemann. La princesa de Baviera, contó con un chófer profesional [fig. 3].

El moderno trazado de la red viaria en España se debió en parte a las inversiones realizadas por el Circuito Nacional de Firmes Especiales (CNFE), en el cual participaron el Estado, las diputaciones y los ayuntamientos. Se recibió la aportación económica procedente de un nuevo impuesto: la tasa de rodaje. El Patronato CNFE nació en 1926 con la idea de dotar al territorio de una red de carreteras bien planificada. Las prioridades fueron comunicar las poblaciones de mayor importancia y crear circuitos de valor histórico artístico. El objetivo fue fomentar el turismo y enaltecer la riqueza cultural de España. En definitiva, las nuevas carreteras eran un reclamo para los viajeros extranjeros ${ }^{24}$. No obstante, hubo algunas voces descalificadoras como las del inglés Percy J. Martin, quien a raíz de su visita a las exposiciones de Sevilla y Barcelona menciona la gran cantidad de baches existentes en las carreteras. Sin embargo, abundaron los elogios a la modernización de las comunicaciones destinadas a los vehículos ligeros frente a las críticas. Además del citado comandante Czermak, encontramos a Charles L. Freeston (1930) o a Le Cor-

${ }^{21}$ La visita al castillo de Mussomeli prov. Caltanisetta (Sicilia) en la fotografía vemos caballos con montura y carruajes usados como medio de transporte. Ebhardt, 1925: vol. V, lám. 277.

22 Ebhardt, 1974: 141-144.

23 Königlich Bayerischer Automobil-Club, 1927: 9; 25.

${ }^{24}$ Gaceta de Madrid, 41, 10.2.1926: 723-725. 


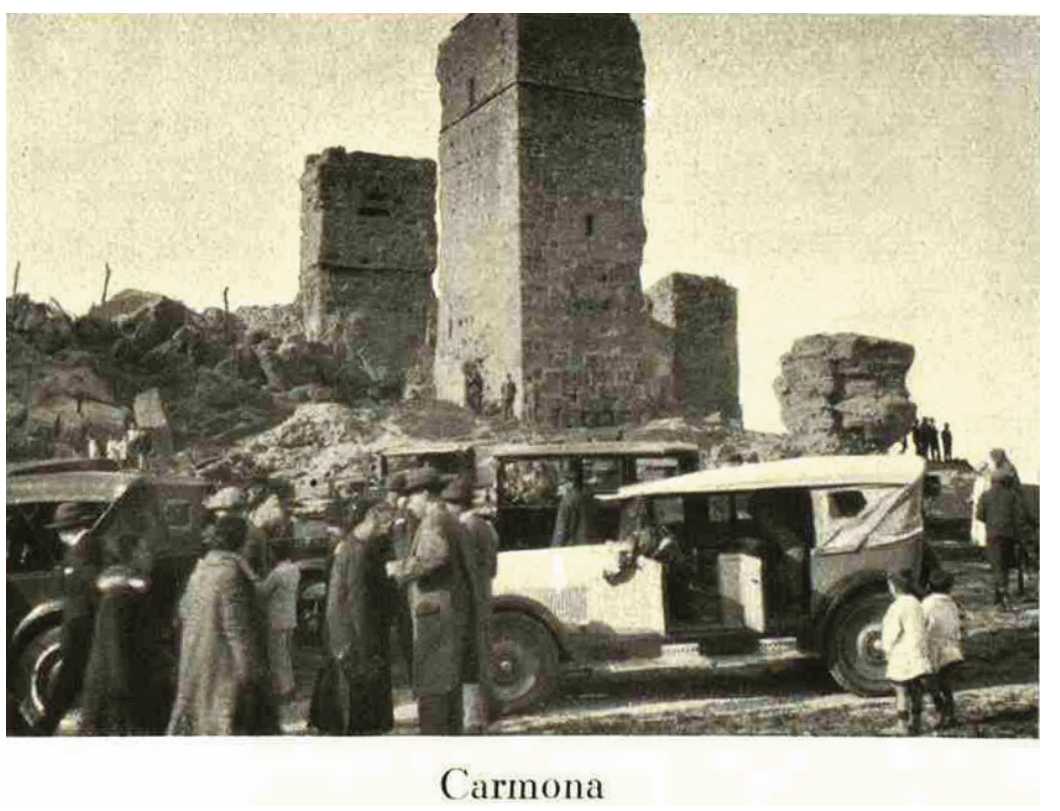

Fig. 3. Carmona. Königlich Bayerischer Automobil-Club, 1927: 27.

busier (1931) ${ }^{25}$. En el mismo tono, Ebhardt no escatimó en aplausos al hablar de las inversiones del dictador "Ribera (sic)". Menciona "una vez más relucientes carreteras", "excelentes", o "muy buenas" y también matiza la construcción de alguna que otra obra de mejora de una carretera existente - Toledo- . El investigador alemán observó las nuevas medidas de seguridad adoptadas para la circulación - las estacas blancas y rojas con una malla de alambre en la zona de Sierra Morena-, el generoso ancho de la vía nada más cruzar la Junquera, o el celo en el diseño de las rasantes y las curvas, por ejemplo, en la carretera de la costa mediterránea. Igualmente, citó los distintos pavimentos de asfalto o de hormigón — Collbató-, según la carretera. El cuidado del firme junto con el esmero de su trazado, favorecieron poder alcanzar velocidades por entonces de vértigo: $100 \mathrm{~km} / \mathrm{h}$. Ebhardt circuló raudamente con su Mercedes, por una vía recta y sin curvas, a la salida de Aranjuez inmediata al río Jarama. Pero no todo fueron halagos, pocas veces según él, el viaje fue incomodo; en los alrededores de Peñafiel confirma "por primera vez mala carretera", e incluso señala que el acceso de algún que otro castillo resultó impracticable -Perelada_ ${ }^{26}$ [fig. 4].

El mismo arquitecto nos reseña la organización de su viaje. En un mapa de la península ibérica localizó los principales castillos; indicó los distintos nombres que habían tenido a lo largo de la historia, y calculó los kilómetros para cada uno de los trayectos ${ }^{27}$. En julio de 1927, Ebhardt, al igual que en sus proyectos anteriores, preparó un primer listado alfabético de castillos a inspeccionar ${ }^{28}$, en la medida de lo posible, todos ellos representaban un hito del pasado del pueblo español, es decir que fuesen testigos de su historia. La selección estaba fundada, en parte, en las respuestas recibidas por carta de los especialistas en la materia — septiembre de 1926 - ${ }^{29}$ junto con sus pesquisas en archivos y bibliotecas.

25 Rodríguez, 2004: 76-87.

26 Ebhardt, 1934: 54, 101-102, 115, 110, 41, 31, 45, 38, 106, 123, 32

${ }^{27}$ Lo preparó de forma similar a su primer viaje por Italia realizado entre el 6 de marzo hasta el 30 de abril de 1902. Tragbar, 1999: 73-74; catálogo 21; 232.

${ }^{28}$ Entre la documentación personal se han encontrado varias propuestas: 9/VII/1927; 30/VIII/1927; 7/VIII/1929.... En cambio, no se ha localizado el mapa que menciona el arquitecto. DBV-Archiv Nr. 2253.

${ }^{29}$ ANC. 1-737-T-1298. 


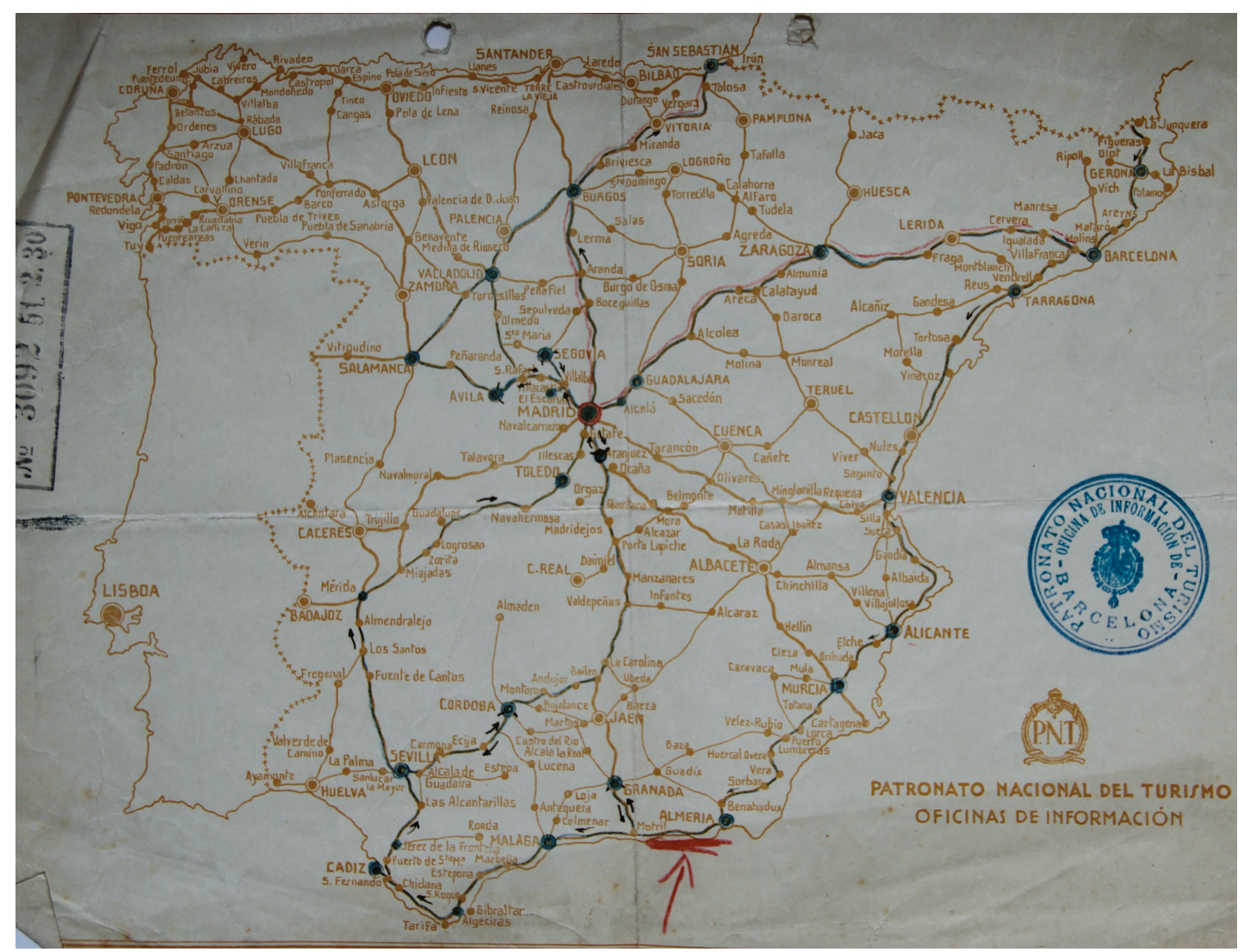

Fig. 4. Plano de carreteras de España [Rutas marcadas por Bodo Ebhardt]. Patronato Nacional de Turismo. s.d. DBV-Archiv 2253.

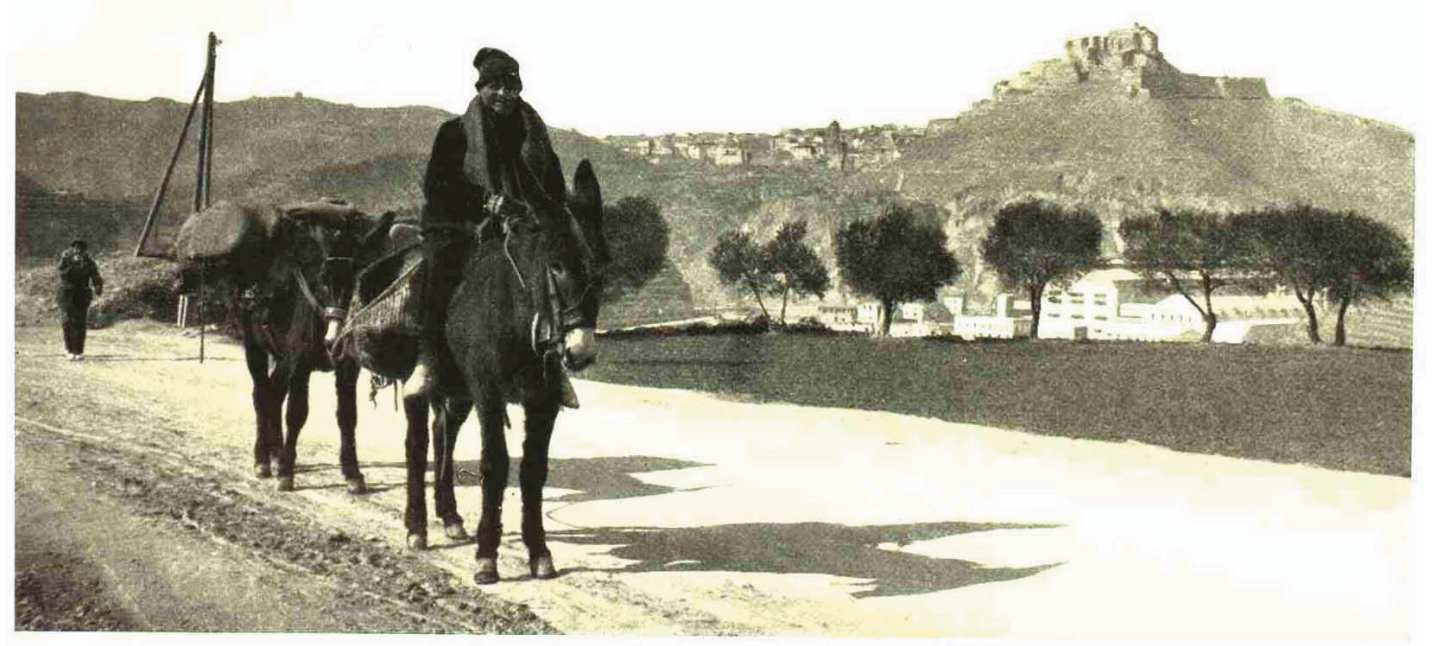

Die Burg Carbont, Bilo Der Embichaft

Fig. 5. Castillo de Cardona, vista del paisaje, Ebhardt, 1934: n. ${ }^{\circ} 8$.

Archivo Español de Arte, vol. XCIII, n. ${ }^{\circ} 369$, pp. 21-38, enero-marzo 2020 ISSN: 0004-0428, eISSN: 1988-8511, https://doi.org/10.3989/aearte.2020.02 
No exploró toda la Península; se interesó en particular por los territorios conquistados al sur de España — en concreto la zona bañada por el Mediterráneo e inmediaciones de Sevilla—, el reino de Aragón y el de Castilla y, en cambio, dejó a un lado el territorio del antiguo reino de León — hoy en día parte del cual pertenece a Portugal—.

Quizás esta visión parcial resultaba más fructífera para preconcebir las formas propias de la arquitectura fortificada levantada en España. Aunque somos conscientes de que la limitación temporal le impidió ampliar el marco geográfico e incrementar el número de castillos estudiados. Tuvo que priorizar; valoró aquellos castillos mejor comunicados o situados cerca de las grandes poblaciones - Barcelona, Madrid, Córdoba o Burgos - . A juzgar por el contenido de la introducción, le hubiese resultado interesante el reconocimiento del castillo de Monzón, para comprobar la presencia de formas árabes en el reino de Aragón, pero prescindió. Otras visitas fueron una decepción, como la del castillo en el coll de Balaguer. No quedaba ni rastro de lo representado en la estampa de Eberhardt ca. 1840. Con sorpresa, Ebhardt escribió que hasta la cimentación la habían volado. Parece claro que el material gráfico con el que planificó su viaje no estaba actualizado ${ }^{30}$ [fig. 5].

Preparó el equipaje con el material necesario para sus investigaciones: varios cuadernos de dibujos, dos cámaras fotográficas de diferente formato, aparatos de medir y una cámara de $\operatorname{cine}^{31}$. Con el propósito de evitar cualquier sobresalto y problemas en su viaje, solicitó una carta de presentación al embajador en Berlín del Reino de España, Fernando Espinosa de los Monteros (1927-1931). Asimismo, el diplomático español le proporcionó algunos contactos. Entre los políticos alemanes podemos citar al embajador en España, al conde Johannes Bernhard Graf von Welczeck (1925-1936); al cónsul general de Barcelona, Rudolf Bobrik (1928-1931); o al cónsul de Sevilla, el sr. Diehl. Entre la aristocracia se cuentan Ramón M. a de Narváez y Pérez de Guzmán el Bueno, conde de Cartago; Luis Beltrán Escrivá de Romaní y de Sentmenat, conde de Sástago y marqués de Monistrol; y María Consuelo Cubas de Erice, condesa de Santa María de la Sisla, casada con el banquero alemán Guillermo Pelizaeus. Gracias al arqueólogo Pere Bosch Gimpera contactó con Jeroni Martorell — quien le mostró Cardona-, con Torres Balbás o con los profesores universitarios Pascual Galindo y Luis Pericot. Además de los bibliotecarios y/o archiveros Jordi Rubió, Andrés Sobejano o José de la Torre, entre otras personalidades ${ }^{32}$.

\section{Financiación y publicidad}

Una empresa como esta requería de financiación externa. No era la primera vez que Ebhardt recurría a una subvención. El emperador Guillermo II, en su empeño por reescribir la historia de Alemania, le había otorgado sustanciosas ayudas tanto para sus investigaciones como para sus proyectos de restauración - castillo de Haut-Koenigsbourg - Podemos mencionar las sucesivas becas de viaje a Italia (1902-1914), así como las estancias en Francia y en Bélgica (1915) ${ }^{33}$. En Italia estudió la recepción de la arquitectura militar germana en ese país; en palabras de Ebhardt: "verificar el alcance de la influencia de los pueblos alemanes"34. Es decir, tenía un claro criterio patriótico. La segunda ayuda se la concedieron con el propósito de documentar las fortificaciones que peligraban ante el adelanto de las tropas francesas y belgas en los dominios del II Reich

30 Ebhardt, 1934: 6, 10, 48.

${ }^{31}$ Ebhardt apuntó los posibles gastos, ayudante -Klaus Bufall-, películas, cámara de fotos, 50 cuadernos de bocetos... Lo que ascendía a 4.400 RM. DBV-Archiv Nr. 2253.

32 Ebhardt, 1934: 11, 10, 12; 1932: s. p. El embajador Espinosa de los Monteros estudió derecho en Madrid y en Alemania. Defendió su tesis doctoral en la universidad de Jena, Die rechtliche Stellung der unehelichen Kinder nach dem deutschen Bürgerlichen Gesetzbuch und dem spanischen Código civil publicada por Borna-Leipzig: Noske, 1909. Hera, 2002: 155. DBV-Archiv Nr. 2240 II.

33 Tragbar, 1999: 72-80. Los resultados se publicaron en seis entregas en libros de gran formato y con un buen número de ilustraciones — dibujos y fotografías-. Ebhardt, 1909-1927. Link, 2014: 156-170.

34 Ebhardt, 1909: 6. 
durante la I Guerra Mundial. Se trató de un viaje de propaganda política. Según Ebhardt, el conflicto bélico se generó con "el único objetivo es ocultar el tamaño de la única patria, Alemania, la grandeza del emperador y del imperio". En ese mismo contexto aprovechó las páginas de su monografía para exaltar la figura de Guillermo II. El propósito fue demostrar al lector el alto grado de innovación científica de los estudiosos alemanes y, a su vez, constatar la preocupación por la defensa y la custodia de su patrimonio por parte del emperador ${ }^{35}$. En definitiva, la época Guillermina (1890-1918) significó un verdadero empuje profesional para Ebhardt. Además, no solo contó con el mecenazgo del emperador sino también con el de la elite aristocrática, muchos de los cuales eran miembros de la DBV, fundada por él en 1899.

Con motivo de la derrota de Alemania en la I Guerra Mundial se modificó el escenario político y cultural. Así, la abdicación del emperador y la desaparición del II Reich trajo consigo un nuevo régimen político: la República de Weimar. Dentro del ambiente intelectual del momento, el interés por España estaba en auge. Los científicos alemanes proyectaban una imagen positiva de España, aunque observaban la tensión existente entre progreso y tradición. A Alemania le interesaba buscar nuevos aliados entre los países que habían permanecido neutrales durante el conflicto bélico. Su objetivo era salir del aislamiento. En estas circunstancias, España se convirtió en un país preferente. Por un lado, podría convertirse en un nuevo socio; pero, por otro lado, era el puente hacia América Latina. La República de Weimar, sin lugar a dudas, era consciente de la necesidad de promocionar los intereses alemanes en el extranjero. Un marco idóneo fueron las entidades académicas en el exterior bajo el patrocinio del Ministerio de Asuntos Exteriores ${ }^{36}$.

Al mismo tiempo, en 1920 se reorganizó el sistema de ayudas a la investigación mediante la creación de un nuevo organismo: Notgemeinschaft der Deutschen Wissenschaft (NDW) ${ }^{37}$. Nació con el claro propósito de reflotar la investigación que peligraba debido a la crisis económica y a la devaluación de la moneda. En los primeros años, los esfuerzos se concentraron en el gabinete de comunicación mediante la publicación de revistas y ensayos. Desde 1924, se inició un programa de becas para la promoción de la innovación. Hubo un especial empeño por fomentar la calidad. Se estableció el modelo Peer-Review. A partir de 1926, se incrementó el número de ayudas y se apostó por programas de mayor alcance. Esta nueva política permitió la creación de una red científica. Aunque no existió una única directriz sí que se establecieron algunas líneas preferentes: innovación tecnológica, bienestar económico y mejora de la asistencia sanitaria ${ }^{38}$.

El tema de los castillos en la república de Weimar no fue prioritario. A pesar de ello, se costearon a través del NDW los últimos volúmenes de Ebhardt Die Burgen Italiens ${ }^{39}$. Asimismo, se becaron a Ebhardt y a Karl-Heinz Clasen en sus viajes de estudio a España y a la antigua Prusia, respectivamente. Es interesante observar cómo ambos historiadores intentaron discernir la presencia de la formulación germana en la arquitectura civil, aunque Clasen constató que existía un prototipo de edificación de los pueblos eslavos. Esta tesis discrepaba con la ratificada anteriormente por Georg Dehio ${ }^{40}$. Y por último, se sufragó el proyecto del grupo de investigación de los 'castillos del noroeste de Alemania'. Este último centró sus esfuerzos en las prospecciones arqueológicas de los castros de la cultura lusaciana en la zona este del Elba y el Saale. Es decir, se promovieron una vez más los estudios en las regiones de la antigua Prusia.

Desde hacía varias décadas se habían forjado lazos de colaboración entre científicos alemanes, españoles y portugueses en lo que atañe a los estudios de la Antigüedad en la península ibérica. Robert Grosse redactó un estado de la cuestión en 1929 en el que destacó la importancia

35 Ebhardt, 1915: 44. Ebhardt comentó: "Pero el Altísimo Señor con todas las preocupaciones sobre las batallas decisivas..., recordaba su antiguo entusiasmo por el arte y la ciencia”, Ebhardt, 1915: 5.

${ }^{36}$ Briesemeister, 2010: 79, 81, 83. Hera, 2014: 58-62; 2002: 36-48. Bernecker, 2000: 117-147. López, 2003: 241247. Janué, 2010: 177, 183, 185, 187; 2008: 22-26.

37 Presas, 2010: 93.

38 Kirchhoff, 2003: 359-377; 242-244; 334-335. Nipperdey, 1970: 17-22; 39-47; 118-119.

39 La falta de subvenciones estatales y la crisis económica no impidieron a Ebhardt la publicación de algunas de sus monografías por la editorial de la DBV. Ebhardt, 1918.

${ }^{40}$ Clasen, 1926: 1-37. 
de Adolf Schulten. También mencionó a otros científicos, Bosch, discípulo de Hubert Schmidt, o Fidel Fitas. Consideraba que esta cooperación se había convertido en un "factor político". Así podemos entender la aportación económica del Institut d'Estudis Catalans a las excavaciones dirigidas por Schulten en $1919^{41}$.

Durante el periodo de Weimar se sufragaron estudios sobre España y se fortalecieron las relaciones científicas hispano-alemanas. A partir de la revista Forschungen und Fortschritte hemos podido documentar las bolsas de viaje y las subvenciones para la publicación de la obra del historiador del arte Georg Weise Spanische Plastik aus sieben Jahrhunderten (1925-1939). Esta serie monográfica contó también con la aportación económica de algunos alemanes residentes en España, como Félix Schlayer ${ }^{42}$. En el campo de la arqueología en particular de la prehistoria, destacan Hugo Obermaier y su discípulo, Julio Martínez Santa-Olalla, que se especializó en la expansión de las tribus germanas - visigodos-. Asimismo, continuaron las campañas arqueológicas de Schulten ${ }^{43}$.

En este orden de cosas, debemos concebir que la ayuda otorgada a Ebhardt estuviera destinada al análisis de las aportaciones de los pueblos germánicos y la cultura hispanomusulmana en los castillos medievales construidos en el territorio español. En la revista Forschungen und Fortschritte expuso su hipótesis de trabajo y algunos de los logros alcanzados, que publicó igualmente en unas galeradas para la promoción de la publicación y en la introducción de su libro sobre España ${ }^{44}$.

Con su viaje buscaba conocer de primera mano el carácter propio de las arquitecturas fortificadas tanto por sus sistemas constructivos como por sus formas artísticas. El objetivo del estudio, en definitiva, era discernir entre lo heredado de los pueblos germanos y la tradición propia de la cultura hispanomusulmana. La mezcla de ambas soluciones derivó en un estilo "característico" de lo español. En palabras del arquitecto alemán:

\footnotetext{
"Los castillos españoles respiran en su conjunto un espíritu de caballería y una grandeza del pensamiento arquitectónico, al menos equiparable a los mayores logros de la construcción de castillos de otros países, y además combinan una peculiaridad de apariencia, la cual solo puede explicarse por el aislamiento del país y por la penetración y la fecundación mutuas que se derivan de una lucha prolongada durante siglos entre dos razas y de dos cosmovisiones" ${ }^{\prime 4}$.
}

También era importante conseguir financiación para publicar sus monografías. Las subvenciones públicas habían menguado drásticamente; ya no contaba con el apoyo incondicional del emperador Guillermo II. La imprenta Burgverlag, editora de la revista Der Burgwart y de algunos ensayos de Ebhardt, se enfrentó a la recesión de posguerra. La escasez de papel, el aumento de los costos, y la baja de algunos socios al estar en los llamados "territorios ocupados por el enemigo" obligaron a subir la cuota entre los asociados de la DBV. A pesar de ello, hubo una buena acogida a la nueva medida económica ${ }^{46}$.

El arquitecto alemán inició una campaña publicitaria para logar un interés por la compra de su libro Spanische Burgenfahrt, 1930: Ein Reisebericht. En el suplemento de Der Burgwart de 1932 se publicó una lista con los primeros treinta suscriptores; el perfil era variado. Encontramos industriales, diplomáticos, médicos, profesores universitarios, ingenieros, arquitectos... residentes en Alemania, Inglaterra o España. Alcanzar un buen número de suscriptores era esencial para poder garantizar una cuidada edición.

Sin embargo, los artículos sobre su viaje publicados en las revistas especializadas también fueron un buen reclamo. Ya hemos mencionado el del boletín Deutsche Bauzeitung (1930) sobre la ciudad de Almería. En cambio, en la revista Der Burgwart se imprimieron galeradas. En par-

\footnotetext{
41 Grosse, 1929: 11-13, 53-62.

42 Weise, 1934: 42. Rückert, 2009: 339, 342.

43 Schulten, 1929: 293-294.

44 Link, 2014: 135, n. 311. Ebhardt, 1931: 49-50; 1932: s. p.; 1934: 5-9.

45 Ebhardt, 1934: 8.

46 Anón. 1919: s. p.
} 
ticular, el suplemento de invitación para el pedido por antelación, y el artículo Küstenfahrt von Tarragona nach Valencia. Aus: Spanische Burgenfahrt son una buena muestra de ello. El primero era un extracto de lo impreso en la revista Forschungen und Fortschritte, tal y como ya hemos adelantado. Comentó las características de la publicación, que contaría con unas 100 páginas, varias fotografías y 34 bocetos del arquitecto. Era un libro pensado para un bibliófilo con "un disfrute especial". En cambio, el contenido del segundo era más propio de unas pruebas de imprenta. No obstante, ni las fotografías, ni los croquis, ni su contenido se reprodujeron en el libro de viaje. Entre otras cosas, prescindió de publicar una foto del puente de hierro de Tortosa o referirse a la torre de los Escipiones. En cambio, profundizó más en otros aspectos: la descripción urbanística de Tarragona o el castillo de Tortosa ${ }^{47}$ [fig. 6].

También divulgó los primeros avances científicos mediante conferencias: Städtebauliches aus Spanien en el marco del día de la arquitectura alemana celebrado en Dresde (6.9.1930); Spanische Burgenfahrt en la asociación de arquitectos e ingenieros de Berlín (24.11.1930), y un año después Spanische Burgen en Coblenza y Erlangen ${ }^{48}$.

La campaña fue un éxito. Reunió el capital suficiente para publicar una edición de lujo, impresa y encuadernada por la firma de Leipzig Spamer AG. La tirada fue reducida, e incluso numerada; recordemos que estaba destinada a un público selecto. Algunos ejemplares contaban con la firma autógrafa de Ebhardt ${ }^{49}$ [figs. 7 y 8].

Las revistas especializadas y la prensa de la época pronto se hicieron eco de la novedad editorial. En septiembre de 1935 el periódico Tiroler Anzeiger menciona la reseña del libro en la revista Alte und neue Welt. La revista científica Zeitschrift für Kunstgeschichte valora el tono de la narración de la experiencia vivida, pero sobre todo los dibujos, los cuales demuestran lo característico de las construcciones militares. Gertrudis Richert, en Ibero-Amerikanisches Archiv, va un poco más lejos y nos comenta que la mirada del artista prevalece en los dibujos, pero también el tono romántico del arquitecto al hablarnos de los personajes típicos. Bettina Feistel-Rohmeder, en Das Bild, recalca lo sugerente de sus impresiones junto con el valor artístico de sus bocetos. La Deutsche Bauzeitung expone el planteamiento teórico al indicar: "como la técnica así también las formas" con el propósito de lograr una clasificación morfológica de las construcciones. Además, considera de vital importancia la relación del monumento con el paisaje. No obstante, lamenta que no exista un interés por comentar las intervenciones o restauraciones efectuadas en los castillos. Una visión más crítica nos la aporta el hispanista Wilhelm Giese, en Volkstum und Kultur der Romanen. Giese argumenta que se trata de un libro divulgativo: habla del país y sus gentes. Los castillos los aborda de forma somera al destacar únicamente sus singularidades, pero los dibujos a mano alzada son de gran calidad. Asimismo, considera que la visión es parcial: no ha visitado el antiguo reino de León, ni Galicia, ni Extremadura. Incluso mejora la escritura de algunos topónimos o nombres propios. No comparte su concepto de "raza española". Aunque la obra sin lugar a dudas va a ser un grato aliciente para los amantes del arte medieval ${ }^{50}$.

\section{Asunto}

Se trata de un libro de viaje y no de un ensayo ${ }^{51}$. Así, lo anecdótico y las opiniones personales adquieren una especial relevancia. El autor recalca: "El diario de viaje no quiere ofrecer más

${ }^{47}$ [Ebhardt], 1932: s. p.; 1933: 25-31. Años después publicará un dibujo del puente de hierro de Tortosa a partir de la foto, Ebhardt, 1958: vol. 2.1, 10, fig. 4.

48 Bekiers, 1984: 307. Fischer, 2010, 253. Der Burgwart, 1931: 74.

49 El ejemplar consultado procede de la biblioteca privada de la familia Krupp en la villa Hügel (Essen), con la referencia Q2416e. Se trata de un volumen numerado y firmado por el autor $-n .^{\circ} 48$ - Custodiado en la Ruhr Universität Bochum (RUB). Sig. N CGA 1.

50 Anón. 1935: 168; Richert, 1935: 141; B. [editor], 1935: 542; Giese, 1935: 368-369. DBV-Archiv Nr. 2240 IV.

51 El análisis de la literatura de viajes no es en sí el objeto de estudio de este artículo. No obstante, podemos establecer ciertas semejanzas entre la obra de Ebhardt y algunos libros de viajes coetáneos. Por ejemplo, el interés por los 


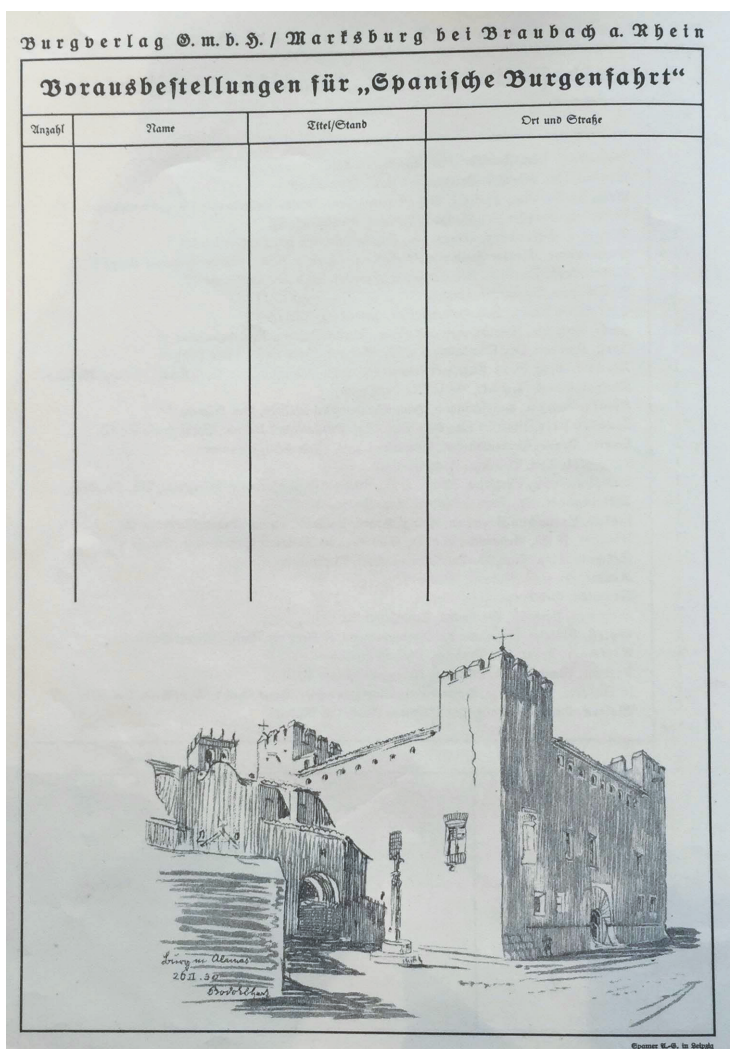

Fig. 6. Hoja de pedido por antelación [Alàquas], Ebhardt, 26.II.30. Der Burgwart, 1932, s. p. geanitche 达urgenfabrt
Ein Keileberichtoon 13000 EbBardt

Ein 通eileberichtoon Bbodo EBBardt

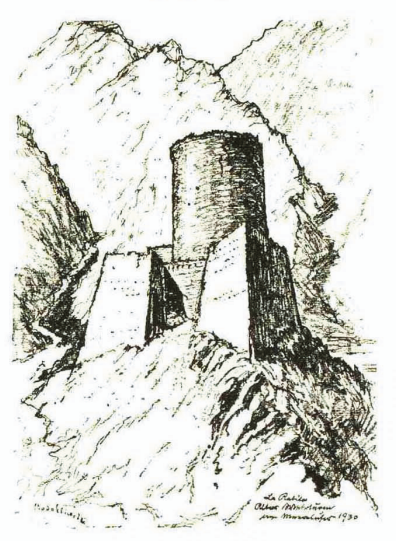

Mit 40 ż6 bifrungen,

34 t5andrizzen im mortfauf und 34 שafeln

nack zeicbnungen des perfalters

Fig. 7. Portada [La Rábita], Ebhardt, 1930. Ebhardt, 1934.
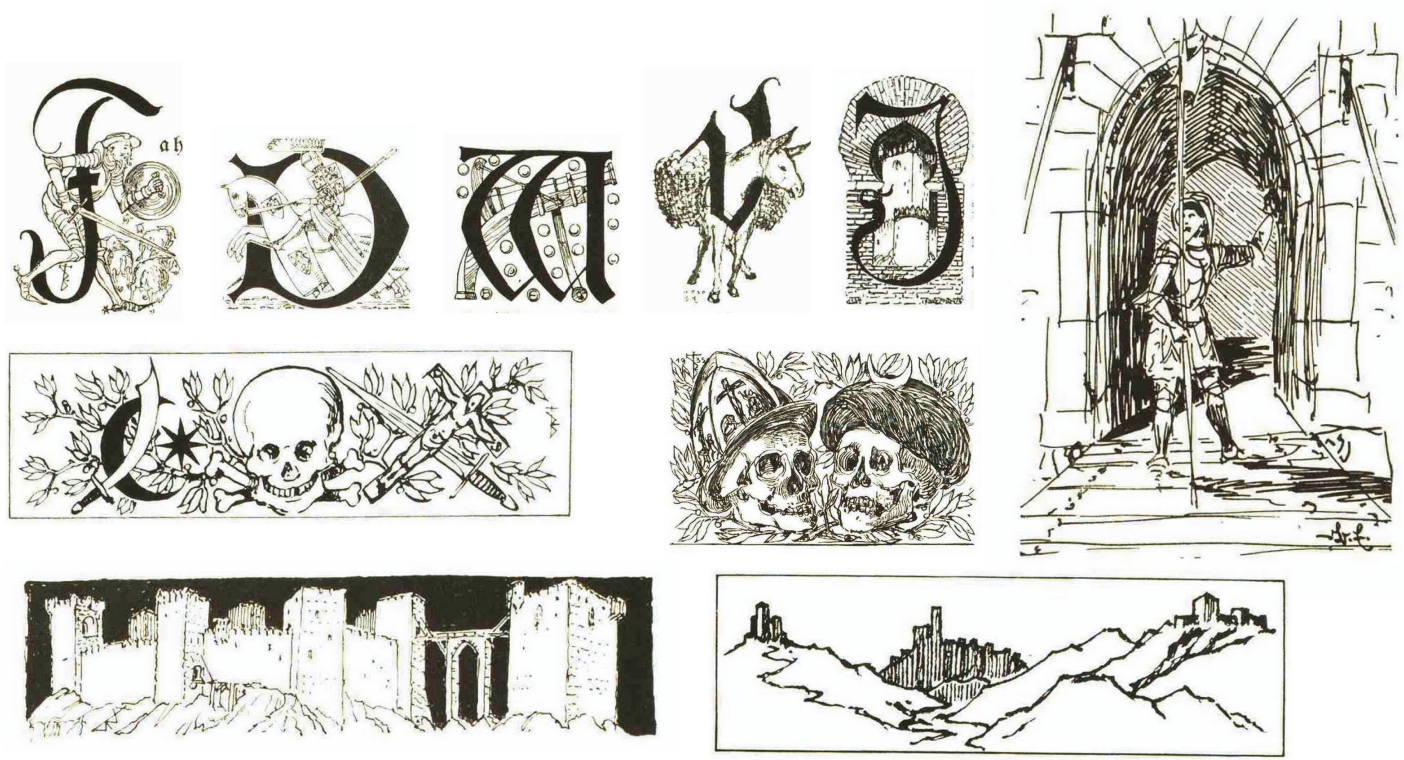

Fig. 8. Capitulares y piezas gráficas. Ebhardt, 1934. 
que una imagen del paisaje español, del trabajo agrícola español, y de la vida fuera de las conocidas grandes ciudades" 52 . Esta misma opinión la corroboran las reseñas del ingeniero Ronn, en Deutsche Technik, o Reinhold Schneider, en Berliner Börsenzeitung ${ }^{53}$. De este modo, la descripción de los castillos pasa a un segundo plano mientras que Ebhardt se entretiene en relatar las aventuras de su visita, las gentes, las costumbres o el entorno, sin olvidar los detalles constructivos o mediciones. Analizó, en particular, los castillos de Almodóvar del Rio, Alcalá de Guadaira, Alaquàs, Aledo, Almería, Antequera, Cardona, Carmona, El Carpio, Coca, Córdoba, Escalona, Fuensaldaña, Guadamur, Játiva, Loja, Lorca, Manzanares el Real, Maqueda, La Mota o Zahara.

El itinerario casi coincide con una de las rutas marcadas en el plano del Patronato Nacional de Turismo [fig. 4]. Recorrió la carretera del Mediterráneo desde la Junquera hasta Almería. Desde allí viajó por el interior dirección Granada, Loja, Málaga, Antequera, Ronda, Zahara y Sevilla ${ }^{54}$. A partir de la capital andaluza se dirigió a Córdoba, Bailen, Valdepeñas, Aranjuez y Madrid. En Madrid permaneció unos días y vistió los castillos en las inmediaciones de Madrid y Toledo. Paseó por Ávila y Segovia. Prosiguió viaje dirección Valladolid, pasando por Olmedo. Desde allí fue a Peñafiel, Aranda y Burgos. Continuó camino a Vitoria hasta llegar a la frontera de Irún. El tono de la narración es más sintético a medida que avanza el viaje. En consecuencia, sus descripciones son más concisas a partir de Segovia — viaje de regreso-.

El toque romántico de su narración lo transmiten sus referencias a los tiempos del Quijote o bien sus descripciones de paisajes escarpados que también inspiraron las láminas de Doré. Se interesa por aspectos populares como la indumentaria tradicional de la zona de Tortosa, de Sierra Morena cerca de Guarromán o de El Carpio. Estos recursos corresponden a una época. Asimismo, los observa Max von Boehn en su manual, que Ebhardt cotejó para su monografía ${ }^{55}$. A lo largo de su narración, intenta atraer la atención del lector con escenas cotidianas como la comida, el hospedaje o los medios de locomoción. Aunque no olvida hablarnos de las minorías étnicas marroquíes o gitanos- e incluso mencionar alguna que otra infravivienda en las inmediaciones de los castillos - Solsona, Ulldecona, Láchar ${ }^{56}$-.

Los prejuicios y los tópicos están presentes en la opinión de sus gentes y de sus costumbres. El sentimiento de pertenecer a un pueblo culto, civilizado y con cierto grado de desarrollo, está insinuado a lo largo de su narración. Comentarios como el de su compatriota, el conde S[isla] lo corroboran: "lo analfabetos españoles son el pueblo más alegre de Europa; aquí se nos aparecen así". Aunque Ebhardt admira el carácter amigable, servicial y discreto de ellos. Incluso compara su talante al de un caballero medieval. Valora su carácter festivo y alegre, propio de la cultura andaluza. Pocas veces, encuentra situaciones incómodas con mendigos o niños impidiendo el desarrollo de su labor. Incluso en Zahara cuando le preguntaron por la situación política, le hablaron del emperador y no de la República. Este punto de vista contrasta con sus juicios sobre el pueblo francés: altivo y sucio ${ }^{57}$ [fig. 9].

La búsqueda de elementos germánicos es una constante. Los observa en los paisajes, en la arquitectura tradicional e incluso en las obras promovidas por Carlos V. La comparación es la base de su formulación. De este modo, intenta ver los pros y los contras de un país y del otro. Por ejemplo, en materia urbanística le desagrada la política de nuevos ensanches con grandes avenidas en Barcelona, Madrid o Valencia, que contrastan con el espíritu conservador del empe-

castillos de España, Ezio Levi (1931); por el dibujo de vistas y monumentos, Benno Elkan (1926) o Roger Fry (1923); o por la fotografía Kurt Hielscher (1922). Este último, Ebhardt lo consultó antes de iniciar su viaje a España. En la República de Weimar otros viajeros alemanes recorrieron España, Münster, 2011: 301-311. A pesar de la difícil situación política entre 1934-35 se publicaron varios libros de viajes por España en lengua alemana. Hera, 2002: 335, n. 203.

52 Ebhardt, 1934: 12.

53 DBV-Archiv Nr. 2240 IV.

54 El recorrido muestra ciertas coincidencias con el modelo clásico de los viajeros ingleses interesados en conocer la costa mediterránea -Henry Swinburne, 1775 a 1776-. Ebhardt cita la monografía Viaje de Gibraltar a Málaga (1777) de Francis Carter, quien recorrió el sur de Andalucía. Pérez, 2008: 218.

55 Ebhardt, 1934: 48; 101; 99. Ebhardt, 1958, vol. 2.1, 1-5.

56 Ebhardt, 1934: 44; 52; 80.

57 Ebhardt, 1934: 112; 108; 144; 61; 81; 90; 15; 17; 141. 


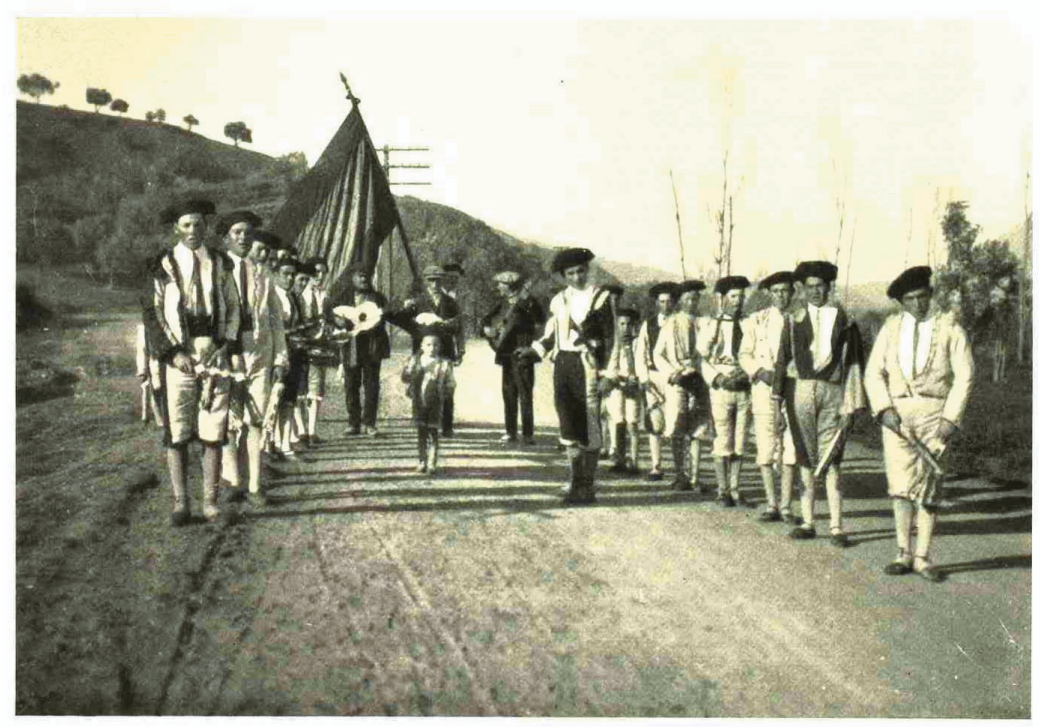

Ränolicher Frinnachtszung bei Loja गir. 22 Fig. 9. Desfile de carnaval en Loja. Ebhardt, 1934: n. ${ }^{\circ} 22$.

rador Guillermo II. Esta nueva estrategia también la advierte en Francia e Italia. Algo similares son sus consideraciones sobre el desamparo en que se hallan los castillos al carecer de un plan de conservación - Cardona, Alaquàs, Loja - aunque otras veces se realizaron algunas mejoras, no se concluyeron - Manzanares el Real-58.

La mirada de las fábricas le facilita indagar sobre el emplazamiento, las peculiaridades del entorno, del paisaje y de sus materiales. La observación desde cierta distancia es propicia para analizar los volúmenes y las formas. Los croquis, las fotografías y las películas son la primera toma de contacto que se complementan después con la medición y el dibujo de algunos detalles. Así, él mismo aseveró: "Buenos planos y vistas pueden permitir al lector formar su propio juicio, pero sobre todo las construcciones deben hablar por sí mismas"59 [fig. 10].

El siguiente paso fue la clasificación morfológica. En ese sentido, sostiene que el primer románico de las iglesias de Cardona, Loarre, Alcañiz o Albalate del Arzobispo refleja la sensibilidad propia de los visigodos, francos y sajones; pero al mismo tiempo muestran su carácter propio. Los volúmenes cuadrados que encuentra en Lorca, Aledo o El Carpio responden a la tradición musulmana ${ }^{60}$. Los sistemas constructivos están vinculados a las distintas tradiciones. Al tapial le ve su origen árabe - Alcalá de Guadaira - y al ladrillo la tradición germánica - Medina del Campo-. Estas apreciaciones son fruto del esquema elaborado en agosto de 1930 por el cual estableció varios aspectos clave para el análisis de los castillos: situación estratégica, materiales constructivos, clima, raza, origen y singularidades ${ }^{61}$.

Esta tipificación va acompañada de un buen número de croquis de elementos arquitectónicos - columnas, arcos o escudos heráldicos- No se trata de una propuesta minuciosa como la que realizó Ruskin en Venecia. No obstante, esta aportación nos permite perfilar su pensamiento y la organización de la información. Este método derivó en un análisis estilístico de las formas como se observa en sus estudios sobre el arco de herradura propio del mudéjar - Alcalá de Guadaira o El Carpio-62 [figs. 11 y 12].

\footnotetext{
58 Ebhardt, 1934: 36; 42; 56-57; 80; 108.

59 Ebhardt, 1939: 4.

60 Ebhardt, 1934: 37-38; 74; 93; 121.

${ }^{61}$ DBV-Archiv Nr. 2253.

${ }^{62}$ Ebhardt, 1934: 40; 93; 100.
} 
Fig. 10. Zahara, vista desde el sur, Ebhardt, 4.3.30. Ebhardt, 1934: lám. p. 86.

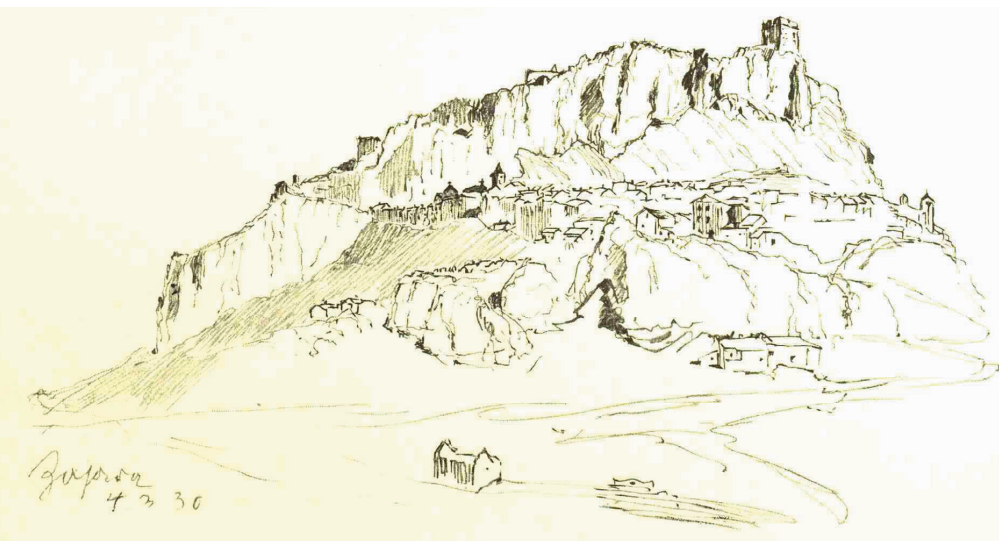

Fig. 11. Lorca, torre del homenaje en el castillo principal, Ebhardt, 1934: n. ${ }^{\circ} 15$.

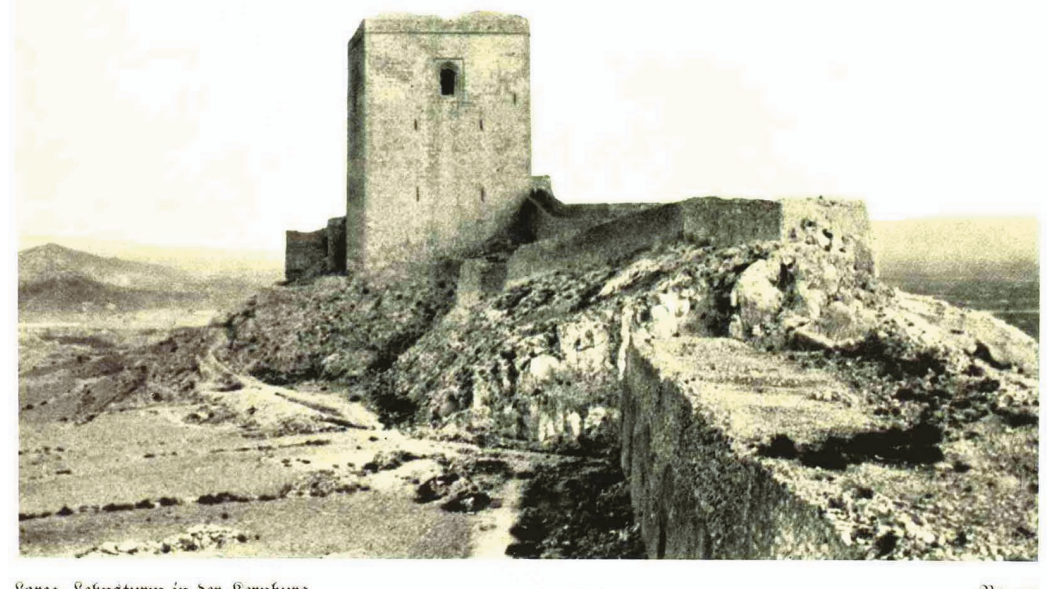

Fig. 12. Lorca, torre y detalles, Ebhardt, 28.II.30 Ebhardt, 1934: lám. p. 68-70; $68 ; 70 ; 69$
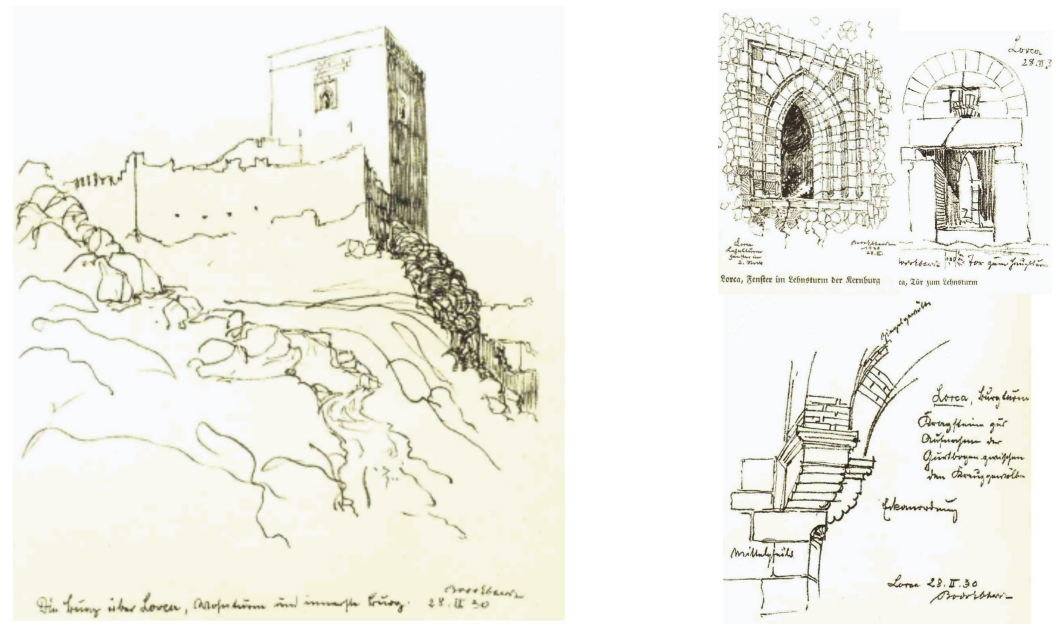

Archivo Español de Arte, vol. XCIII, n. ${ }^{\circ} 369$, pp. 21-38, enero-marzo 2020 ISSN: 0004-0428, eISSN: 1988-8511, https://doi.org/10.3989/aearte.2020.02 


\section{Conclusión}

La recepción de la obra de Ebhardt en el panorama español de la época fue más bien escasa. La prensa se hizo eco de su reconstrucción fantasiosa del castillo de Haut-Koenigsbourg, y la revista La Construcción Moderna menciona su participación en 1908 en el Congreso de Arquitectura de Viena, al cual no asistió ${ }^{3}$.

No obstante, Ebhardt sí manejó bibliografía en español, aunque él mismo comenta sus escasos conocimientos del idioma. Durante el viaje compró alguna que otra postal y un buen numero de fotos del arxiu Mas o del fotógrafo Otto Wunderlich ${ }^{64}$. Ricardo Martín Mayobre le facilitó las publicaciones impresas, informes y documentación gráfica sobre los castillos españoles. También le asesoró Franz Babinger y contó con el apoyo del Deutsches Kulturinstitut en Madrid. En este contexto se entiende que cotejase las últimas novedades editoriales en su obra Der Wehrbau Europas im Mittelalter ${ }^{65}$.

Sin duda, amplió las fuentes de estudio después de su viaje a España. Su libro de viaje contiene escasa referencias bibliográficas. No obstante, citó a Charles Daviller, Gustave Doré o a Francis Carter. Sabemos que conocía otras monografías, por ejemplo, el ensayo del urbanista Oskar Jürgens cuyo contenido comenta, aunque sin mencionar al autor ${ }^{66}$. Recordemos que se trataba de un libro divulgativo.

El panorama era distinto en su ensayo de 1958. En esa ocasión, sí especifica la bibliografía e incluso las fuentes que examinó para elaborar la planimetría — el plano de Játiva ${ }^{67}$ lo modificó una vez consultado el texto de Carlos Sarthou- Amplió sus conocimientos gracias a autores coetáneos como Vicente Lampérez y Romea, Jeroni Martorell, Felipe B. Navarro, Carlos Sarthou Carreras, Federico Carlos Sainz Robles, o Francisco Layna Serrano. No obstante, el intercambio no fue siempre recíproco; Sarthou desconocía el libro de Ebhardt al escribir su monografía ${ }^{68}$. A pesar del esmero y del cuidado en las citas bibliográficas, no todas son lo suficientemente precisas ${ }^{69}$. El mismo autor se justifica al referirse a los problemas que encontró a raíz del conflicto armado tanto con el préstamo interbibliotecario - nacional e internacional - como con las pérdidas materiales ${ }^{70}$.

En definitiva, su libro nos ha permitido constatar la importancia del viaje científico como método de estudio. Existía una larga tradición de historiadores del arte alemanes. Entre los trabajos que precedieron a Ebhardt podemos citar Carl Justi o Julius Meier-Grafe. Ebhardt dio a conocer en el ámbito de habla alemana los castillos medievales de España. Gracias a su labor se alcanzó una visión más global del fenómeno de los castillos en Europa.

\section{BIBLIOGRAFÍA ${ }^{71}$}

Fuentes originales

Europäisches Burgeninstitut Einrichtung der Deutschen Burgenvereinigung e.V Braubach (DBV-Archiv).

Arxiu Nacional de Catalunya (ANC).

\footnotetext{
${ }^{63}$ Anón. (1919b): s. p.; Anón. (1908b): 364; Anón. (1908): 92.

${ }^{64}$ Ebhardt, 1934: 105; 61; 9.

${ }^{65}$ Ebhardt, 1958: vol. 2.2, 702-703.

66 Jürgens no analizó Almería. Ebhardt, 1934: 76.

${ }^{67}$ Ebhardt, 1934: 60; 1958: vol. 2.1, 118 fig. 96.

68 Giese, 1950: 463-464.

${ }^{69}$ Elude al autor Rodrigo Amador de los Ríos y Fernández de Villalta (1907-1912) en Monumentos Arquitectónicos de España, Madrid: E. Martín y Gamoneda.

70 Ebhardt, 1958: vol. 2.2, 718.

71 “Arte y Patrimonio Moderno y Contemporáneo" (GR18101-HUM012) dirigido por M. a Lozano Bartolozzi. Para la elaboración del mismo se recibió una bolsa de viaje cofinanciada por la Consejería de Economía, Ciencia y Agenda Digital (Junta de Extremadura) y el Fondo Europeo de Desarrollo Regional mediante la ayuda a grupos de investigación. (RUB).

Agradezco la ayuda de la Prof. Dr. Cornelia Jöchner y de la Dr. Yvonne Northemann de la Ruhr-Universität Bochum
} 
Anón. (1908): "VIII Congreso Internacional de Arquitectos. Viena, 1908”. En: La Construcción Moderna, año VI, 5, Madrid, pp. 90-92.

Anón. (1908b): "Reconstrucción del Castillo Haut- Koenigsbourg". En: La hormiga de oro, año XXV, 6.6.1908, p. 364.

Anón. (1919): “An die Mitglieder der Vereinigung zur Erhaltung deutscher Burgen”, Der Burgwart, 20, 1, Berlín-Grunewald, 1919, s. p.

Anón. (1919b): "Un castillo histórico". En: Alrededor del Mundo, año XXI,1034, 24.3.1919, s. p.

Anón. (1935): “Notizen und Nachrichten”. En: Zeitschrift für Kunstgeschichte, vol. 4, 3, Berlín, p. 168.

B. [editor] (1935): "Neue Bücher". En: Deutsche Bauzeitung, 27, 3.7, Berlín, p. 542.

Bekiers, Andreas (1984): Bodo Ebhardt: Architekt, Burgenforscher, Restaurator; 1865-1945; Leben und Frühwerk bis 1900. Berlín: Schütze.

Bernecker, Walter (2000): "Nuevas tendencias en la historiografía alemana sobre España. Temas, enfoques, resultados". En: Historia Contemporánea, 20, Leioa, pp. 117-147.

Briesemeister, Dietrich, (2010): "España en Alemania: sobre el desarrollo de la investigación en los siglos XIX y XX". En: Rebok, Sandra (coord.), Traspasar Fronteras. Un siglo de intercambio cientifico. Madrid, CSIC/DAAD, pp. 57-85.

Clasen, Karl-Heinz (1926): "Entwicklung, Ursprung und Wesen der Deutschordensburg". En: Jahrbuch für Kunstwissenschaft, 3, Múnich-Berlín, pp. 1-37.

Dollen, Busso von der/ Schock-Werner, Barbara (1999): Burgenromantik und Burgenrestaurierung um 1900: Der Architekt und Burgenforscher Bodo Ebhardt in seiner Zeit. Braubach: DBV.

Doering, Oskar (1925): Bodo Ebhardt: Ein deutscher Baumeister. Berlín-Grunewald: Burgverlag.

Ebhardt, Bodo (1901): Die Grundlage der Erhaltung und Wiederherstellung Deutscher Burgen. Vortrag gehalten auf dem Ersten Tag für Denkmalspflege in Dresden im September 1900. Berlín: Wilhelm Ernst \& Sohn.

Ebhardt, Bodo (1905): Über Verfall, Erhaltung und Wiederherstellung von Baudenkmalen: Mit Regeln für praktische Ausführungen. Berlín: Franz Ebhardt \& Co.

Ebhardt, Bodo (1909-1927): Die Burgen Italiens. Berlín: Wasmuth; Oberitalien. (1909) (Vol. 1); Oberitalien. (1910) (Vol. 2); Mittel-Italien. (1916) (Vol. 3); Unteritalien. (1917) (Vol. 4); Süditalien und Sizilien. (1925) (Vol. 5); Verzeichnis italienischer Burgen nach Namen, Lage, Art, Erhaltung, Geschichte, Besitzer und Quellen nebst Hinweis auf ihre Erwähnung in Bd. 1-5. (1927) (Vol. 6).

Ebhardt, Bodo (1915): Krieg und Baukunst in Frankreich und Belgien, Berlín-Grunewald: Burgverlag.

Ebhardt, Bodo (1918): Die zehn Bücher der Architektur des Vitruv und ihre Herausgeber seit 1484, Berlín-Grunewald: Burgverlag.

Ebhardt, Bodo (1930): "Kraftwagenfahrt durch Spanien. Ein Besuch Almerias". En: Deutsche Bauzeitung. Stadt und Siedlung, vol. 63,15, Berlín, 5.10.1930, pp. 105-108.

Ebhardt, Bodo (1931): "Eine Burgenstudienfahrt durch Spanien”. En: Forschungen und Fortschritte, VII, 4, 1.2.1931, Berlín, pp. 49-50.

[Ebhardt, Bodo] (1932): “Spanische Burgenfahrt von Bodo Ebhardt. Einladung zur Vorausbestellung!”. En: Der Burgwart, 33, Marksburg ob Braubach, s. p.

Ebhardt, Bodo (1933): “Küstenfahrt von Tarragona nach Valencia. Aus: Spanische Burgenfahrt”. En: Der Burgwart, 34, Marksburg ob Braubach, pp. 25-31.

Ebhardt, Bodo (1934): Spanische Burgenfahrt, 1930: Ein Reisebericht, Marksburg: Burgverlag.

Ebhardt, Bodo; Ebhardt, Fritz, DBV (1935): Bodo Ebhardt: Handzeichnungen: Festschrift. Berlín: Verlag für Kunstwissenschaft.

Ebhardt, Bodo (1939): Der Wehrbau Europas im Mittelalter: Versuch einer Gesamtdarstellung der europäischen Burgen. Vol. 1. Berlín: Deutsche Verlagsgesellschaft.

Ebhardt, Bodo (1958): Der Wehrbau Europas im Mittelalter: Versuch einer Gesamtdarstellung der europäischen Burgen. Vol. 2.1; Vol. 2.2. Berlín: Deutsche Verlagsgesellschaft.

Ebhardt, Klaus (1974): "Bodo Ebhardt 1865-1945". En: Burgen und Schlösser - Zeitschrift für Burgenforschung und Denkmalpflege, 15, 2, Braubach, pp. 141-144.

Faensen, Hubert (2018): Die Neue Hakeburg. Wilhelminischer Prachtbau, Hitlers Forschungszentrum, SED-Kaderschmiede. Berlín: Ch Links Verlag.

Fischer, Ludger (1999a): "Mittelalterliche Architektur "richtig nachgeahmt” Bodo Ebhardts Stil". En: Dollen, Busso von der/ Schock-Werner, Barbara: pp 157-169.

Fischer, Ludger (1999b): "Bodo Ebhardts Beitrag zur Fachliteratur und Kommentiertes Schriftenverzeichnis von Bodo Ebhardt". En: Dollen, Busso von der/ Schock-Werner, Barbara (eds.): pp 212- 228.

Fischer, Ludger (2010): Bodo Ebhardt - Versuche baukünstlerischer Denkmalpflege: Restaurierungen, Rekonstruktionen und Neubauten von Burgen, Schlössern und Herrenhäusern von 1899 bis 1935. Braubach: DBV.

Fischer, Ludger (2015): "Zum 150. Geburtstag von Bodo Ebhardt”. En: Burgen und Schlösser - Zeitschrift für Burgenforschung und Denkmalpflege, 2, Braubach, pp. 2-7.

Giese, Wilhelm (1935): “Besprechungen”. En: Volkstum und Kultur der Romanen, VIII, Hamburgo, pp. 368-369.

Giese, Wilhelm (1950): “Reseñas de libros”. En: Thesaurus. Boletín del Instituto Caro y Cuervo, tomo VI, 3, pp. 463-464.

Gil Crespo, Javier (2016): "Bodo Ebhardt y los castillos españoles: notas sobre su obra de restauración y su pensamiento europeísta y pangermánico”. En: Revista de Historiografía (RevHisto), 24, Madrid, pp. 245-272.

Grosse, Robert (1929): "Deutsche Altertumsforschung in Spanien”. En: Wissenschaftliche Beilage zum Jahresbericht 1928/1929, Bamberg: Buchner. 
Hera Martínez, Jesús de la (2002): La politica cultural de Alemania en España en el período de entreguerras. Madrid: CSIC.

Hera Martínez, Jesús de la (2014): "Ciencia y propaganda (El instituto alemán de cultura de Madrid y sus antecedentes: 1924-1945)”. En: Iurisprudentia Elegans: Revista de Derecho Político e Historia Constitucional, 1, Madrid, pp. 57-75.

Janué Miret, Marició (2008): "La cultura como instrumento de la influencia alemana en España: la sociedad GermanoEspañola de Berlín (1930-1945)”. En: Janué Miret, Marició (ed.): España y Alemania: Historia de las relaciones culturales en el siglo XX. Madrid: Marcial Pons / Asociación de Historia Contemporánea, pp. 21-45.

Janué Miret, Marició (2010): "La ciencia y la cultura alemanas como espejo: pensionados de la Junta para Ampliación de Estudios e Investigaciones Científicas (JAE) en Alemania”. En: Rebok, Sandra (coord.), Traspasar Fronteras. Un siglo de intercambio cientifico. Madrid, CSIC/DAAD, pp. 169-191.

Kirchhoff, Jochen (2003): Wissenschaftsförderung und forschungspolitische Prioritäten der Notgemeinschaft der Deutschen Wissenschaft 1920-1932. Dissertation. Múnich: LMU.

Königlich Bayerischer Automobil-Club (1927): Autofahrten quer durch Spanien. Múnich: Mühlthaler.

Kubach, Hans Erich/Verbeek, Albert (1951): "Die vorromanische und romanische Baukunst in Mitteleuropa. Literaturbericht 1938 bis 1950". En: Zeitschrift für Kunstgeschichte, vol. 14, 1, Berlín, pp. 124-148.

Link, Fabian (2009): "The Internationalism of German Castle Research: Bodo Ebhardt, His European Network, and the Construction of 'Castle Knowledge"'. En: Public Archaeology, vol. 8, 4, XI, Leeds, pp. 325-350.

Link, Fabian (2014): Burgen und Burgenforschung im Nationalsozialismus: Wissenschaft und Weltanschaung 19331945. Colonia: Böhlau.

Link, Fabian (2015): "Castle Studies and the Idea of Europe: Medievalism in German-Speaking Europe between Politics and Scientific Research, 1918-1945”. En: German Studies Review, 38, 3, Baltimore, pp. 555-572.

López Sánchez, José María (2003): “Política cultural exterior alemana en España durante la República de Weimar”. En: Cuadernos de Historia Contemporánea, 25, Madrid, pp. 235-253.

Münster, Reinhold (2011): "Vision und Wirklichkeit. Deutsche Spanienreisende von der Jahrhundertwende bis zum Dritten Reich (1900-1933)". En: Raposo Fernández, Berta/ Gutiérrez Koester, Isabel (eds.): Bis an den Rand Europas: Spanien in deutschen Reiseberichten vom Mittelalter bis zur Gegenwart. Fráncfort del Meno: Vervuert, pp. 275-314.

Nipperdey, Thomas (1970): 50 Jahre Forschungsförderung in Deutschland: Ein abriss der Geschichte der deutschen Forschungsgemeinschaft, 1920-1970. Bonn: Deutsche Forschungsgemeinschaft (DFG).

Oechelhäuser, Adolf von (1910): Auszug aus den stenographischen Berichten des Tages für Denkmalpflege in Dresden... 1900-1909, vol. 1 Vorbildungs- und Stilfragen, Gesetzgebung, staatliche und kommunale Denkmalpflege. Leipzig: Seemann.

Pérez Berenguel, José F. (2008): "La figura de Henry Swinburne y las características de su viaje por España". En: Cuadernos dieciochistas, vol. 9, pp. 211-228.

Presas Puig, Albert (2010): "Las relaciones científicas entre Alemania y España durante los años 20”. En: Rebok, Sandra (coord.), Traspasar Fronteras. Un siglo de intercambio cientifico. Madrid, CSIC/DAAD, pp. 87-104.

Richter, G. (1935): "Literaturbericht". En: Ibero-Amerikanisches Archive, vol. 9, 2, p. 141.

Rodríguez Lázaro, Francisco Javier (2004): Las primeras autopistas españolas (1925-1936). Madrid, Colegio de Ingenieros de Caminos, Canales y Puertos.

Rückert, Claudia (2009): "Georg Weise y la Hallenkirche española". En: Anales de Historia del arte, 1, Madrid, pp. 229246.

Schulten, Adolf (1929): “Archäologische Probleme in Spanien”. En: Forschungen und Fortschritte, V, 26, 10.09.1929, Berlín, pp. 293-294.

Tag für Denkmalpflege, (1901): Zweiter Tag für Denkmalpflege. Stenographischer Bericht. Karlsruhe: Müller'sche Hofbuchdruckerei.

Tragbar, Klaus (1999): "Burgenstudien in Italien”. En: Dollen, Busso von der/ Schock-Werner, Barbara (eds.): pp. 73-74; cat. 21, p. 232.

Weise, Georg (1925-1939): Spanische Plastik aus sieben Jahrhunderten, vol. I; vol. II.1, II.2; vol. III.1, III.2; vol. IV. Reutlingen: Gryphius-Verlag.

Weise, Georg (1934): "Die Erforschung der spanischen Plastik". En: Forschungen und Fortschritte, X, 4, 1.02.1934, Berlín, p. 42-43.

Fecha de recepción: 18-XII-2018

Fecha de aceptación: 10-VI-2019 